\section{EMBRYRIDDLE \\ Aeronautical University}

SCHOLARLY COMMONS

\section{International Journal of Aviation,} Aeronautics, and Aerospace

\title{
Literature Review of GA Pilots Transition to Advanced Cockpit Technologies
}

John A. Kolmos

York College/CUNY, jakolmos@gmail.com

Follow this and additional works at: https://commons.erau.edu/ijaaa

Part of the Adult and Continuing Education Commons, Curriculum and Instruction Commons, Educational Assessment, Evaluation, and Research Commons, Educational Methods Commons, and the Educational Psychology Commons

\section{Scholarly Commons Citation}

Kolmos, J. A. (2018). Literature Review of GA Pilots Transition to Advanced Cockpit Technologies. International Journal of Aviation, Aeronautics, and Aerospace, 5(2). https://doi.org/10.15394/ ijaaa.2018.1235

This Literature Review is brought to you for free and open access by the Journals at Scholarly Commons. It has been accepted for inclusion in International Journal of Aviation, Aeronautics, and Aerospace by an authorized administrator of Scholarly Commons. For more information, please contact commons@erau.edu. 
A positive change that can be made for students by the research conducted by educational psychologists is in the area of adult education. Specifically, in the area of aviation and the transition of older pilots to technically advanced aircraft (TAA) and avionics. The learning process for these older pilots, those over 40 and 50 years of age should be approached perhaps in a different manner than the present. The training and instructional programs are now geared towards a one size fits all and problems seem to surface according to the literature affecting particularly older pilots.

\section{Older Pilots and the Need for a Positive Change in Learning}

Navigating an aircraft is a complex, time consuming and a highly pressured activity and one that needs for the aged pilot, specifically, to be explored in regards to new avionic technologies and their ability to safely transition to complex avionics. The "...older aviators, who typically experience age-related declines in cognitive abilities and visual acuity, these factors may play an even greater role during adverse weather conditions" (Kennedy, Taylor, Reade, \& Yesavage, 2010, p. 489). O'Hare and Owen have stated that pilots equipped with more advanced avionics showed an increase in accident rates. "Comparing the numbers continuing on [in clouds] with those not continuing [visual conditions] shows a marginally significant difference between those using Global Positioning System (GPS) and those not" (O'Hare, \& Owen, 2001, p.80). O'Hare and Owen (2001) also state "that as a result of the flight simulation study there is a tendency for pilots using a GPS navigation system [like the G-1000] in VMC [visual meteorological conditions] tend to behave differently from pilots using more older methods of navigation, and at least two of these factors in decision making are age and recent flight experience," (p. 81).

Hamblin, Gilmore, and Chaparro (2006) in their paper Learning to Fly Glass Flightdeck Requires a New Cognitive Model state that "there can be a negative correlation with pilot's total flying time and their greater experience in traditional avionics may have more difficulty transitioning to TAA [Technically Advanced Aircraft, i.e. computer screens]" (p. 1979). There have been many studies of this using the quantitative methodologies. In setting the stage for a change in educational psychology and the need to understand learning for older adults this paper will present the following research.

In the Kennedy et al. (2010) article looking at older pilots, in particular, the sampling size used to conduct the testing of older pilots/younger pilot's verses moderate experience/high experience consisted of 72 pilots, 19 - 79 years of age, with two levels of IFR experience. The first level was moderate experience defined 
as having a rating of IFR (instrument rated, allows pilots to fly in poor visibility and low cloud conditions) or CFI (certified flight instructor). High experience, which was having a rating of CFII (certified flight instructor for IFR students) or ATP (certificated to fly air-transport aircraft). The study was modeled so that half the group were less than 40 years of age and the other half were 40 years and older. The two groups were further divided so that half of the under 40-year-olds were of moderate experience and the other half were considered high expertise. The second group was also divided the same way. Eligibility required a current FAA Medical Certificate.

Equipment used was a Frasca 141 flight simulator. "The simulator was linked to a computer specialized for graphics (Dell Precision Workstation and custom C11 OpenGL Linux software) that generated a "through-the-window" visual environment and continuously collected data concerning the aircraft's position and communication frequencies" (Kennedy, Taylor, Reade, \& Yesavage, 2010, pp. 490-491). The software was designed to collect flight data regarding the accuracy of landings and holding pattern decisions. The project occurred during the hours from 0900 to 1600 ; pilots had the preference of choosing the time to participate in the simulation. The procedure was to fly three ILS approaches (Instrument Landing System) to runway 30 at SJC (San Jose airport) with a 200' DH (decision height above the ground) (Kennedy, Taylor, Reade, \& Yesavage, 2010).

The three approaches were either a touch-and-go or a missed approach. Instrument meteorological conditions were present with visibility set to approach minimums, and another approach conditions we set to below minimums for the approach (Kennedy, Taylor, Reade, \& Yesavage, 2010, pp. 490-491). Each subject was to do two turns in the hold and then to be vectored to a 6-mile final (Kennedy, Taylor, Reade, \& Yesavage, 2010, pp. 490-491). In conclusion, the study showed that according to Kennedy, et al., (2010)

The negative correlation found between performance on the dual task cognitive measures and age suggests that age-related differences may be due to decrements in attention rather than decision making per se. However, the dual task cognitive measures did not significantly predict flight performance. Only speed of processing performance accounted for the age-related differences in aileron control. The results indicate that age-related declines in cognitive ability may affect certain aspects of flying an aircraft. (p. 495) 
In other words, the results are shown above, as well as some of the solutions that may be found in the literature may provide guidance on the cognitive learning that pilots, especially older pilots whose experience is in conventional aircraft, can be efficiently utilized in a different approach to learning. The AOPA (Aircraft Owners and Pilots Association) through the Air Safety Foundation, a division of AOPA, states "More and better simulation is gradually becoming available to TAA pilots....Training to use nontraditional avionics using traditional methods is not optimal"'(AOPA Air Safety Foundation, 2007, p.52). The TAA Safety Study Team in their report of August 22, 2003 states that "Overall TAA training should rely greatly on various levels of simulation, beginning with computer-based part task trainer for each major TAA system on the aircraft, and moving up to an integrated flight deck simulator for scenario-based training" (TAA Safety Study Team, 2003, p.19). "Research shows that computer-based training in conjunction with a desktop flight simulator can improve significantly the speed at which transition pilots acquire knowledge and skill, particularly for glass-flight decks navigation," (Mitchell, Chappell, Gray, Thurman, \& Quinn, 2001, p. 453).

Looking how the CBI (Computer Based Instruction) is designed and implemented, taking into consideration the age and experience of the pilot, will have a significant effect on the transfer of learning from conventional to TAA. Suzanne K. Kearns in her book E-Learning in Aviation states "Clearly, the effectiveness of any e-learning [CBI] course will be directly linked to how the course is designed" (Kearns, 2010, p.28). The point that Kearns makes is essential in the fact that how the course is designed and how effective it is in producing the desired results is the starting point for designing a course of study for the older pilot. The results to be looked at would be pilots, especially those 40 years of age and over, which have had many years using conventional avionics, through a properly designed and executed course, making a successful transition to TAA aircraft safely. The ideal would be to locate and put to use such a design for those pilots looking into transitioning to TAA. Has the research been looked into for such a course design and what would it consist of? Looking at the Kennedy et al. (2010) article in their concluding remarks states

Our findings suggest that providing older pilots with focused training in the flight simulator for situations that can carry a high degree of risk in real life, coupled with speed of processing training may be an ideal way to improve older aviators' flight safety. (p. 496) 


\section{Learning Theories to Improve Older Aviators Performance Constructivist Theories}

Constructivism is a learning theory by which a person comes to understand the information already possessed which has already been learned through that person's experiences. It has its foundation in cognitive psychology, and its approach to education emphasizes that knowledge come to fruition to adapt to the world the person is operating in. Constructivist learning is just that, a constructive process where the learner is building internal knowledge from personal experiences that to which they have been exposed. This knowledge does not deny the real world but contends to understand it within the context of the persons own understanding of it. A person grows from sharing these perspectives and by responding to new perspectives or experiences changing their internal understanding (Bednar, Cunnigham, Duffy, Perry, 1995). The challenge of constructivism is when a person changes by letting go of control from learning from the instructor to the student (Bednar, Cunnigham, Duffy, Perry, 1995). The student is encouraged to achieve agreed upon objectives (Bednar, Cunnigham, Duffy, Perry, 1995).

The objectives should be designed around the students' needs. This is based on their activities which emerge from the lives lived in the context of their understanding and worldview. The students should be working together with their peers in the social construction of the meanings that are significant to them, and the evaluation should not only be personalized but ongoing, it should be a shared analysis of their progress (Hanckbarth, S., 1996, p.11). Bednar et al., (1995) stated

Agreeing with this view of knowledge, learning must be placed in a rich context, reflective of real-world context, for this constructive process to happen and transfer to environments beyond the school or training classroom. Learning through cognitive apprenticeship, mirroring the collaboration of real world problem solving, and using the tools available in problem solving situations, is key. How effectual or instrumental the learner's knowledge structure is in facilitating thinking in the content field is the measure of learning. (pp.103-10)

\section{Strengths and Weakness of Constructivism Theory}

One of the strengths of this theory is that students learn by experimenting, not by being told what to do but discovering it for themselves (Mayer, 2004; Kirschner, Sweller, and Clark, 2006). This can enhance and strengthen a learner's knowledge and experience in an area of study. This leads to its weakness. While 
perhaps good for experienced students it may not be so for the novice. The argument is that "learning by doing" strengthens learning, however, critics say that this strategy has little evidence for support with novice learners (Mayer, 2004; Kirschner, Sweller, and Clark, 2006). Sweller's article argues that novices do not have the experience of developed mental models that would be necessary for a "learn by doing" method (Sweller, 1988). Mayer (2004) also reviewed the literature and found that the data over the last fifty years supports this and that situations with novices should be guided.

\section{Applying Constructivism in Educational Practice}

In this context, these older pilots are experienced in the aviation field, so constructivist ideas would work well in this area of adult education. Pedagogy deals in the area of instruction with children were as instruction of adults has been referred to as andragogy. The andragogical methodology takes into account differences in learning with the understanding that adults have experiences and existing schemas from life than children do. The theory of constructivism stress that cooperative learning environment based on mutual planning and learning the needs of the student. The objectives are diagnosed needs and interest, which is foundational to the student's ultimately reaching their goal. This is relevant because of the involvement that the learner has in their progress to understand key concepts that are involved in the principle being applied using or emphasizing constructivism in adult education.

The study of cognition has many applications for educational psychology. Teachers need to help students learn by way of organizing information and thereby helping the student to relate one thing to another (Skinner, 1968). Information that is new will usually be acquired when a person associates one thing for another already learned. The teacher can then help a student understand new ideas by relating them to old ones; this would be positive transference (Skinner, 1968). Learning will be slowed however if that person is having trouble relating this new information to the old. It will become ineffective (Skinner, 1968).

From an operate conditioning perspective B.F. Skinner (1968) has stated that students should be actively responding if learning is to be achieved. Cognitivists emphasize mental activity as opposed to physical, believing that if students have control the student would then decide what information is needed. 


\section{Scaffolding}

The FAA has stated: "Pilot training will require emphasis and focus on higher order thinking skills to help pilots learn how to think instead of simply what to think" (as cited in FAA, 2003, p. 12). Higher order thinking has been addressed using scaffolds as instructional procedures to provide temporary support for student's initial learning before they reach intended goals (Palincsar, 1986b). Scaffolding is an important instructional concept because of the process it uses in guiding a learner from what they presently know what is to be known. Vygotsky (1978) wrote that the notion of scaffolding was developed from "zone of proximal development" theory, which is, "the distinction between the actual developmental level as determined by independent problem solving and the level of potential development as determined through problem-solving under adult guidance, or in collaboration with more capable peers" (Vygotsky, 1978, p. 86). Hogan and Pressley (1997) discuss scaffolding as modeling behaviors desired by offering explanations and having the students participate in their verification of understanding the material.

Teaching Bloom's Taxonomy (Bloom, 1956) is a scaffolding device to improve higher order thinking (Hogan and Pressley, 1997). Through intellectual support, scaffolding is used as an instructional device that provides the cutting edge of cognitive development to individual students (Hogan \& Pressley, 1997).

Metacognitive skills, psychological type for heightened self-awareness, authentic learning, and cooperative learning - all cognitive processes and strategies used during problem solving are a part of scaffolding (Brown, 1987). The absence of such an integrated framework of scaffoldings can cause students to mindlessly and superficially attempt to problem solve without consideration of whether that idea makes sense on its own or how it integrates with other ideas (Pressley, Wood, Martin, King, \& Menke, 1992).

\section{Understanding Adult Learning}

The field of adult education has grown since Malcolm Knowles devised the term 'andragogy' which describes the way adults learn compared to pedagogy, or the way children learn (Henschke, 2009). Andragogy is based on certain assumptions that as a person matures:

1. Their self-concept as it moves to being more independent (Watkins \& Marsick, 2014). 
2. They accumulated knowledge from experience (Watkins \& Marsick, 2014).

3. Their readiness about social roles (Watkins \& Marsick, 2014).

4. What is most relevant to them at the time (Watkins \& Marsick, 2014).

5. Their learning is centered on the problem at hand (Watkins \& Marsick, 2014).

6. Learning is intrinsic and provides the motivation (Knowles, 1984:12).

Educational theories have matured over time and andragogy may not be as widely accepted as it once was. The teaching of adults does have its challenges, and the practice of adult education does have some exclusivities particular to it (Watkins \& Marsick, 2014). Adult education may have moved beyond andragogy, nevertheless according to Merriam, Caffarella, and Baumgartner (2007) research has shown over the past decade for adult learning that learning from experience and their learning being self-directed are essential for adult understanding (Watkins \& Marsick, 2014). The discussion of adult educational development is a growing specialty in psychology that provides an understanding of an individual's learning preferences and capacity; as well as the cognitive science that has added to our understanding of how the brain functions in all developmental stages (Watkins \& Marsick, 2014). Educational psychology may have advanced beyond the terms understood as andragogy as a 'field of study' and moved beyond, however, adult learning is still learning how one beyond school age develops their skills from higher education through the workplace or even professional development. (Watkins \& Marsick, 2014).

\section{How Constructivism and Scaffolding Used in Unison can Affect Change with Older Pilots}

Constructivism considers mutual planning important by taking into account the learning the needs of the student. It is built as stated earlier in this paper, on a cooperative learning environment with the objective of achieving and forming learning objectives that are based on the interest of the student.

Scaffolding, on the other hand, looks at the higher order of thinking skills that a pilot must use. It takes the learner from what is known to what is to "be" known. Scaffolding is designed to model the desired behavior or change in the student by offering explanations and engaging the student and verifying that the student understands the information presented to them. Its aim is the higher order of thinking as presented by Bloom's Taxonomy (Bloom, 1956) by providing the necessary intellectual support the student needs. It is ideal for having students push the envelope of comfort and going a little beyond their comfort zones without being 
handheld by an instructor. It builds on the metacognitive skills along with cooperative learning for problem-solving; it is these cognitive processes that allow the necessary strategies to develop for learning, especially in adults who are task oriented toward the goal that is set before them, such as learning a new avionics platform.

By combining constructivism, mutual planning and understanding the specific needs of the student with clear objectives together with developing the higher order of thinking skills to carry out the task by using the constructive blocks of Bloom's Taxonomy (Bloom, 1956) and the development of HOTS (Higher Order of Thinking Skills), the older pilot can more easily transition to a very different type of avionics platform.

\section{Analyzing the Evidence}

Recent studies about age and learning have shown that even though some cognitive degradation occurs with age, the ability and desire to learn of older people are not significantly different from younger people when the learning is specifically changed to address their slower learning rate and need for positive reinforcement (Broady, Chan, \& Caputi, 2010). Broady, Chan, \& Caputi (2010) showed that recent training and positive experiences could efficiently counteract the challenges of cognitive losses due to age.

Constructivism, as written earlier in this paper, has its roots in cognitive and biological sciences. Its emphasis is the different ways for example that knowledge is created to help one adapt to their environment. Learning is a constructive process, one block building on another. It comes from cumulative experiences and sharing of different ideas and then changing one's internalized response to those ideas or views (Bednar, Cunnigham, Duffy, Perry, 1995). A pilot with already some years of flying have a strong background in aviation that guided constructivism provided by the facilitator for the pilots need in transitioning can have a positive effect in their learning and adaption to the new avionics platforms (Loyens et al. 2008). This, however, cannot be self-regulated instruction but guided positive reinforcement coupled with a scaffolding methodology (Loyens et al. 2008; Brown, 1987). Homko (2011) in his research article stated

What can be taken from this observation is an understanding that older people could well be taught to use technology in much the same way as younger people are taught. However, the literature also suggests that at least two additional considerations are necessary for designing computer and technology education for older learners. 
First, consideration must be given to allow ample time for older people to master new skills. Second, care must be taken to treat any person learning to use technology in a positive manner that makes them feel like they are valued, and that success is the expected outcome. While it is true that these two points ought to be considered for all learners, they nonetheless mainly pertain to older users. (p. 15)

Looking at the two suggestions that Homko makes, constructivism guided by way of scaffolding under a properly trained facilitator would help to fill this need. In constructivism with the student and facilitator together they plan and diagnose the learner's needs and interests, which then can be appropriately designed. Using scaffolding together with the constructivism designed earlier, the facilitator can develop the proper guidelines with the student for developing the supportive strategies needed to reach that higher order of thinking skills these aging pilots will need to use the computerized avionics platforms necessary for their vocations. Together it will help bridge the learning gaps older pilots are having with the new systems by changing the way the curriculums are taught today.

\section{Conclusion}

In the literature review, it was shown that age and pilot effectiveness in cognitive abilities do deteriorate and that in more advanced designs such as TAA aircraft, the effect is even more pronounced. It was also shown in the data analysis of the NTSB reports that pilots overall above the age of 40 in both glass and conventional flight deck are having more problems in aircraft accidents and incidents in comparison to their younger peers. The training industry as a whole needs to look at the recommended training programs as stated in the report put out by the AOPA in regards to TAA aircraft and even conventional aircraft overall.

Glass flight deck training requires system knowledge and cognitive training on regular and systematic bases. In other words, the old idea of training to pass a test was perhaps useful in its time, but with advanced aircraft avionics and the complications of the National Airspace System and the subsequent implementation of NextGen (Next Generation Air Traffic Control), this is proving not to be enough. Ground-based training must also pull away from just the generic aircraft specific in the realm of the glass flight deck classrooms. Pilots need to demonstrate that they possess at least the minimum knowledge of aircraft instrumentation and displays to safely operate their aircraft that are equipped with these more advanced avionics platforms. 
The literature review and the data have also shown that through a properly designed program and instruction any pilot regardless of age can improve his/her performance to acceptable levels to perform safe and successful flights in transitioning to TAA aircraft. In speculating on how this learning problem with older pilots can perhaps be addressed in the future, I would suggest scenario-based training (SBT). SBT is according to Summers et al. (2007)

...where the instructor introduces real-life situations for the development of the pilot. This training is a scenario-based approach to training pilots. It emphasizes the development of critical thinking and flight management skills, rather than solely on traditional maneuver-based skills. The goal of this training philosophy is the accelerated acquisition of higher-level decision-making skills. Such skills are necessary to prevent pilot-induced accidents. (p.4)

As seen from this statement from Summers et al. (2007) that SBT would adapt well to the pairing of constructivism and scaffolding.

With pilots transitioning to more advanced flight deck designs and higher performance aircraft, SBT provides a means of teaching pilots how to stay ahead of their aircraft. With the advances in avionics in today's flight decks, the needs for increased technical skills are apparent. If these skills are lacking the potential for accidents will be compounded. A new way of instructing and teaching is required to have pilots, especially older pilots, the transition to these new platforms (Summers et al., 2007).

Scenario-based training, similar to what FAR parts 121 and 135 use in their training programs known as LOFT or Line Oriented Flight Training. This exposes pilots to real-world scenarios under the guidance of a flight instructor in a controlled environment to experience situations a pilot alone may not be able to handle. These advanced flight deck avionics platforms require the pilot to be properly trained and motivated under new learning theories in understanding the cognitive development of aging pilots to safely operate in the world of TAA. Coupling the learning theories of constructivist theory with scaffolding theory fits very well with scenario-based training and can have the positive effect especially on older pilots transitioning to these more complicated avionics platforms. Proper facilitator training in these concepts used with scenario-based training having each block building on the next according to the needs of the individual pilot will help to develop the higher order of thinking skills and reaction for these older pilots that may ultimately produce the desired outcome of effective learning. 


\section{References}

AOPA Air Safety Foundation, (2007). Technically advanced aircraft safety and training. Retrieved from http://www.aopa.org/asf/publications/topics/TAA2007.pdf

Bednar, A. K., Cunningham, D., Duffy T. M. \& Perry J. D. (1995). Theory into Practice: How do we Link? In G. J. Anglin (Ed), Instructional Technology: Past, present and future. Englewood, CO: Libraries Unlimited, pp 100-112.

Bloom, B. (1956). Taxonomy of educational objectives. New York, NY: David McKay Co.

Broady, T., Chan, A., \& Caputi, P. (2010). Comparison of older and younger adults $^{6}$ attitudes towards and abilities with computers: Implications for training and learning. British Journal of Educational Technology, 41 (3), 473-485.

Brown, A. L. (1987). Metacognition, executive control, self-regulation, and other more mysterious mechanisms. In F. Weinhart \& R. Kluwe (Eds.), Metacognition, motivation, and understanding (pp. 65-116). Hillsdale, NJ: Lawrence Erlbaum Associates.

FAA. (2003). FAA-Industry Training Standards (FITS) Program Plan. Oklahoma City, OK: Department of Transportation. Washington, D.C.: U.S. Government Printing Office

Hackbarth, S. (1996). The Educational Technology Handbook. New Jersey: Englewood Cliffs.

Hamblin, C. J., Gilmore, C., \& Chaparro, A. (2006). Learning to fly glass flightdecks requires a new cognitive model. Proceedings of the Human Factors and Ergonomics Society 50th Annual Meeting, 1977-1981.

Harada, E., Mori, K., \& Taniue, N. (2010). Cognitive aging and the usability of IT based equipment: Learning is the key. Japanese Psychological Research, 52(3), 227-243. 
Henschke, J. A. (2009). Beginnings of the history and philosophy of andragogy 1833-2000. In V. Wang (Ed.), Integrating adult learning and technology for effective education: Strategic approaches. Hersey, PA: IGI Global.

Hogan, K., \& Pressley, M. (1997). Scaffolding student learning: Instructional approaches and issues. Cambridge, MA: Brookline Books.

Homko, C. J. (2011). The effects of age and recency of experience on the completion of complex tasks in a Technically advanced aircraft.(Master's thesis, Purdue University), Available from ProQuest. (1501836).

Kearns, S. K. (2010). E-learning in aviation. Burlington, VT: Ashgate.

Kennedy, Q., Taylor, J. L., Reade, G., \& Yesavage, J. A. (2010). Age and expertise effects in aviation decision making and flight control in a flight simulator. Aviation, Space, and Environmental Medicine, 81(5), 489-497.

Kirschner, P. A.; Sweller, J.; Clark, R. E. (2006). Why minimal guidance during instruction does not work: an analysis of the failure of constructivist, discovery, problem-based, experiential, and inquiry-based teaching. Educational Psychologist 41(2), 75-86. doi:10.1207/s15326985ep4102.

Knowles, M. S. (1950). Informal adult education: A guide for administrators, leaders, and teachers. New York, NY: Association Press.

Knowles, M. S. (1984). Andragogy in action: Applying modern principles of adult education. San Francisco, CA: Jossey-Bass.

Loyens, S. M., M., Rikers, R. M., J., P., \& Schmidt, H. G. (2008). Relationships between students' conceptions of constructivist learning and their regulation and processing strategies. Instructional Science, 36(5-6), 445462. doi: http://dx.doi.org/10.1007/s11251-008-9065-6

Mayer, R. (2004). Should there be a three-strikes rule against pure discovery learning? The case for guided methods of instruction. American Psychologist 59(1), 14-19. doi:10.1037/0003-066X.59.1.14.

Merriam, S.B., Caffarella, R. S., \& Baumgartner, L M. (2007). Learning in adulthood: A comprehensive guide. ( $3^{\text {rd }}$ ed.) San Francisco, CA: JosseyBass. 
Mitchell, C. M., Chappell, A.R., Gray, W.M., Thurman, D.A., \& Quinn, A.B. (2001). Intelligent tutors for aviation automation mitigating the problem". Proceedings of the Human Factors and Ergonomics society 45th Annual Meeting - 2001.

O'Hare, D., Owen, D. (2001). "The 'where' and the 'why' of cross-country VFR crashes: database and simulation analyses". Proceedings of the Human Factors and Ergonomics Society 45th Annual Meeting-2001, 78-81.

Pressley, M., Wood, E., Martin, V. E., King, A., \& Menke, D. (1992). Encouraging mindful use of prior knowledge: Attempting to construct explanatory answers facilitates learning. Educational Psychologist, 27(1), 91-109.

Skinner, B.F., (1968). The Design of Experimental Communities. International Encyclopedia of the Social Sciences (Volume 16). New York, NY: Macmillan.

Summers, M., Ayers, F., Connolly, T., \& Robertson, C. (2007). Managing risk through scenario based training, single pilot resource management, and learner centered grading. Retrieved from http://www.faa.gov/training_testing/training/fits/guidance/media/RM_thor ugh_SBT.pdf

Sweller, J. (1988). Cognitive load during problem solving: Effects on learning. Cognitive Science 12(1), 257-285. doi:10.1016/0364-0213(88)90023-7.

TAA Safety Study Team Federal Aviation Administration, (2003). General aviation technically advanced aircraft FAA-industry safety study. Retrieved from http://www.faa.gov/training_testing/training/fits/research/media/TAA\%20 Final\%20Report.pdf

Vygotsky, L. S. (1978). Mind in society. Cambridge, MA: Harvard University Press.

Watkins, K. E., \& Marsick, V. J. (2014). Adult education \& human resource development: Overlapping and disparate fields. New Horizons in Adult Education \& Human Resource Development, 26(1), 42-54. 